\title{
correspondence
}

\section{What about the peace prize?}

SIR,-I am not surprised that, in the normal way, the only Nobel Prizes to which you pay attention (27 October, page 744) are the prizes for physics, chemistry and physiology and medicine. This year, however, scientists have cause to take particular pleasure in the award of the Peace Prize. The 1977 Nobel Prize for peace was awarded to Amnesty International, who-as your own columns have not infrequently reported-have often been involved with helping scientists among the many prisoners of conscience for whom they work.

University of Bristol, UK

\section{J. A. EADES}

\section{Limited tenure}

SIR - Both the present Director of the Imperial Cancer Research Fund, Dr Michael Stoker, and his successor, Professor Walter Bodmer, are on record as believers in "the virtues of limited tenure as a means of maintaining high quality in research". These are finc, high-sounding epithets, but what they actually mean for scientists carrying out research during short contracts is something totally different.

The majority of indigenous talent in cancer research in England is recruited at the doctoral or immediately postdoctoral levels; very often the "virtues of limited tenure" brutally mean-get out by the age of thirty, or certainly not much later. Nobody engaged in activities other than scientific research in the same institute, from the administrators to the catering staff, receive such cavalier treatment; indeed, it would be against the law. Often the PhD student or post-doctorate will feel it necessary to justify himself to his superiors by working long hours, to the detriment of his social life, if not his health. Certainly this will maintain high output, if not also "high quality in research". In addition, the financial return compares badly with many other professions, quite apart from such incidental mishaps as the refusal of building societies to grant mortgages because an income cannot be guaranteed for the appropriate period of time. And of course the searing intellectual corrosion, the shame, the agonising losses of selfconfidence and self-respect that characterise the phase of unemployment and readjustment-inevitable in many cases-these are the price each individual has to pay for having done a highly skilled job cheaply and to the best of his ability.

It is perhaps unfair to single out the ICRF for blame in a situation in which the market for research scientists is presently glutted by talent of an exceptionally high order in virtually all scientific disciplines; in which the governing principles of employment in grant-aided research for those not medically qualified are primarily cheapness and expendability as opposed to merit or achievement. It is easy to spread an ambivalent gloss over the realities of the situation by glamorising the advantages of shortterm appointments as a means of achieving academic excellence, though even this is a highly questionable thesis. Conversely, it is perniciously wrong that gifted young people, often guided into cancer research for reasons that have nothing in common with self-advancement, should be called upon to pay such a bitter and a heavy price for their altruism.

Tübingen, West Germany

ROBERT JONES

\section{Funding of basic research in chemical thermodynamics}

SiR,-The membership of the 1977 Calorimetry Conference is decply concerned with the continuing decrease in funding of research in chemical thermodynamics, especially thermochemistry and thermophysics, and the resultant decrease in data productivity in this field in the past several years. Examination of publications and of Calorimetry Conference programmes shows the greatest decrease to be in the areas of heat capacity measurements and of heat effects in chemical reactions (combustion calorimetry, solution calorimetry, etc.). These are the primary sources of new thermodynamic data for science and technology.

In North American universities, experimental expertise is in danger of being lost in important areas, particularly combustion calorimetry. Programmes in heat capacity calorimetry and in reaction-solution calorimetry are also suffering. Attention is called to the following points:

The production of fundamental thermophysical and thermochemical data for new materials, and for materials not previously studied, is not now sufficient for the evaluation of new processes and applications. Many key areas are no longer being studied. These fundamental data are required for effective research and development in virtually all aspects of energy and technological materials programmes.

The precise determination of the appropriate properties of carefully selected 'key compounds' is important because the data provide anchor points for making critically evaluated estimates and correlations of the properties of whole classes of compounds. This allows the data base to bc expanded greatly on the basis of a relatively small number of carefully chosen measurements.

Acquisition of new data of technological significance on a realistic time scale requires continuous funding to keep available the highly sophisticated equipment and manpower in laboratories necessary for encrgy-related measurcments, in other words, to maintain capability. The initial investment that has already been madc could be lost if sufficient funding is not continued.

Continued acquisition of fundamental calorimetric data has been demonstrated as an important endcavour in the solution of practical problems in many areas of science and technology. It is an economical endeavour. lcading to increased efficiency in the choice of materials, the design of production facilities, energy conservation, and the selection of appropriate large-scale technology.

Fundamental thermodynamic data are also necessary for the critical testing and evaluation of theoretical advances in chemistry.

The conference urges that governmental, private, industrial, and university laboratories, in the light of the above comments, consider their anticipated needs for chemical thermodynamic information and identify the level of support required (manpower and facilities) to supply the information at a rate commensurate with the need.

Particularly where substantial funding reduction has occurred-perhaps originally as a temporary measureconsideration should be given to restoring support on a continuing basis.

Assurance of multi-year support rather than a strict year-by-year support is recommended because of the resulting economies and because the production of high quality data requires a continuity of trained and cxperienced experimentalists. Yours faithfully, Chart.es E. IIOt.t.ey Calorimetry Conference Committee, University of California, USA 